\title{
Exploring wearin and wearout in web advertising: the role of repetition and brand familiarity
}

SANG Y. LEE

sang.lee@mail.wvu.edu

Follow this and additional works at: https://researchrepository.wvu.edu/faculty_publications

Part of the Mass Communication Commons

\section{Digital Commons Citation}

LEE, SANG Y., "Exploring wearin and wearout in web advertising: the role of repetition and brand familiarity" (2010). Faculty Scholarship. 1166.

https://researchrepository.wvu.edu/faculty_publications/1166

This Article is brought to you for free and open access by The Research Repository @ WVU. It has been accepted for inclusion in Faculty Scholarship by an authorized administrator of The Research Repository @ WVU. For more information, please contact ian.harmon@mail.wvu.edu. 


\title{
Exploring wearin and wearout in web advertising: the role of repetition and brand familiarity
}

\author{
Sang Yeal Lee* \\ Perley Isaac Reed School of Journalism \\ West Virginia University \\ 309 Martin Hall \\ Morgantown, WV 26506, USA \\ E-mail: sang.lee@mail.wvu.edu \\ *Corresponding author

\section{Yong-Suk Cho}

Department of Advertising \& Public Relations

Hansei University

Seoul, South Korea

E-mail: adcho@hansei.ac.kr

\begin{abstract}
One of the most researched variables in advertising is repetition. Due to its theoretical and practical importance, repetition has received substantial attention from researchers. However, on the web, there has been little empirical evidence as to how repetition affects advertising effectiveness. This research reports an experiment that examined the effects of repetition and brand familiarity in the web advertising environment. The participants were exposed to 1 of 12 experimental conditions via the web. The results showed that while repetition had weak main effects across the dependent variables, it interacted with brand familiarity on attitudes and purchase intention. Polynomial trend analyses also identified the potential wearin and wearout patterns as a function of repetition when the brand was unfamiliar, but not when the brand was familiar.
\end{abstract}

Keywords: wearin; wearout; web advertising; repetition; brand familiarity.

Reference to this paper should be made as follows: Lee, S.Y. and Cho, Y-S. (2010) 'Exploring wearin and wearout in web advertising: the role of repetition and brand familiarity', Int. J. Electronic Marketing and Retailing, Vol. 3, No. 1, pp.82-96.

Biographical notes: Sang Yeal Lee is Advertising Sequence Chair and an Assistant Professor in the Perley Isaac Reed School of Journalism at West Virginia University, USA. He holds a PhD in Mass Communications from the Pennsylvania State University. His research interests include internet advertising, message framing and psychological distance. He teaches on advertising campaigns, advertising research, and advertising and society.

Yong-Suk Cho is an Assistant Professor of Advertising \& Public Relations at Hansei University in South Korea and is the Director of the Korean Advertising \& Public Relations Society. He has more than 20 years of experience in advertising at major advertising agencies in South Korea and 
holds a PhD in Advertising and Public Relations from Chung-Ang University, Seoul, Korea. His research focuses on psychological and cultural aspects of advertising. He teaches on advertising campaigns, advertising copywriting, and advertising strategy and planning.

\section{Introduction}

Although advertising repetition has received substantial attention from researchers over last several decades, there still remains ambiguity in terms of how repetition affects advertising effectiveness. It seems the ambiguity comes primarily from two reasons. First, the effects of advertising involve many variables and, therefore, isolating the effects of repetition may not mean much since there are many other variables that may moderate the effects of repetition. Thus, when other variables are factored into the study, repetition may lead to totally different results. Second, understanding the role of repetition in advertising is often complicated due to the fact that the relationship between repetition and advertising effectiveness is not linear. Specifically, although the repetition models proposed over the last several decades provide different predictions, one commonality among the existing repetition models is that the increase or 'wearin' of advertising effectiveness eventually begins to 'wearout' after a certain level of exposure due to the tedium or boredom caused by repetition of ads. Wearin refers to the significant positive effect, which usually occurs during the initial few exposures in traditional media. An ad is said to have worn out if it no longer has significant effect or even results in a significant negative effect (Pechmann and Stewart, 1988). Thus, the tedium point can be considered the point of exposure where wearin and wearout are separated and, therefore, has been equated with optimal repetition in advertising.

In the web advertising environment, the role of repetition is even more complicated to understand due to the medium's distinct characteristics. For example, the web provides an environment where users engage in a more active communication process than they would in traditional mass media. Because of this 'active engagement', web users tend to pay attention mainly to the objects that they are interested, while ignoring or paying significantly less attention to others that they are not interested in, such as advertisements. Moreover, existing research suggests that advertising wearout on the web would occur faster than in traditional media. Past research suggests that there is a phenomenon called 'banner burnout', which proposes that advertising effectiveness in terms of banner click-through rate reaches its maximum point at the first exposure and then wears out fast (Pagendarm and Schaumburg, 2001).

To date, research on wearin and wearout effects has focused on traditional media (Schumann and Clemons, 1989; Schumann et al., 1990; Burnkrant and Unnava, 1987) and the empirical evidence that explains the wearin and wearout effects in the web environment is scarce. The current study attempts to identify potential tedium points in the web context under varying brand familiarity conditions. 


\section{Literature review}

\subsection{Wearin and wearout in advertising}

Research on wearin and wearout is often complicated because of two reasons. First, researchers generally agree that the impact of repetition is nonlinear and the pattern of effects caused by repetition is difficult to predict. Secondly, there are many factors and conditions that affect or moderate the impact of repetition. Some of these factors are related to the study conditions (e.g., lab vs. field, ad exposure interval), while others are related to ads (e.g., type of appeals, media, dependent measures, etc.).

There have been several influential models that explain the impact of repetition. The Two-Factor theory proposed by Berlyne (1970), for example, suggests that the impact of repetition is mediated by two factors: habituation and tedium. According to this theory, repetition can take the form of an inverted- $U$ curve in which there are two separate opposing psychological processes operating simultaneously: 'positive habituation' and 'negative tedium'. Berlyne (1970) argues that positive habituation can lead to an increase in affect with diminishing returns of each additional exposure, while, as a result of repetitive exposures, tedium sets in, which would decrease affect rather rapidly.

Krugman (1972), however, provided a different perspective. He proposed the Three-Hit theory, which posits that an ad reaches maximum effectiveness at the third exposure. Krugman argues that repetition one, two and three each have 'special qualities'. The first exposure is unique because it elicits 'cognate response' to understand the nature of the stimulus. The second exposure is more evaluative, and results in 'personal cognate response'. The third exposure is the 'true reminder' since the viewer has already gone through his/her cognitive process. He further argues that "there is no such thing as a fourth exposure psychologically; rather, fours, fives, etc., are just repeats of the third-exposure effect". Thus, the Three-Hit theory can be thought of as an S-shaped response curve. Early studies indicated that attitudes toward the ad (Aad), attitudes toward the brand (Abrand), purchase intentions as well as positive cognitive responses peak at the third exposure (Cacioppo and Petty, 1979). However, it should be noted that Krugman's explanation is based on unfamiliar brand ads and it may well be that familiar brand ads would result in different results.

Pechmann and Stewart (1988) proposed the Two-Stage Cognitive Response Model, which explains the inverted-U curve response of advertising in terms of 'wearin' and 'wearout'. They suggest that, in the first stage, wearin occurs during approximately the first three exposures, whereas after the third exposure, positive thoughts finally outnumber negative thoughts. The second stage begins with approximately the fourth exposure where message recipients become bored. As a result, message recipients generate negative repetition-related thoughts, undermining the persuasive impact of the advertisement. Pechmann and Stewart's model, however, may be appropriate for explaining attitudinal effects of repetition and it is not clear whether their two-factor model can be applied to cognitive variables such as recall and recognition. This is because unlike attitudes and affects, memory does not decline easily as long as there is additional exposure. In other words, boredom, as a result of repetitive exposure, can tire consumers and thereby contribute to negative feelings toward the ad. However, as Pechmann and Stewart (1988) stated, it is not likely that boredom would cause decline in memory. 
Contemporary researchers, on the other hand, argue that an inverted U-curve or $\mathrm{S}$-shaped curve is rare in the real world, and that the more frequently observed model is a concave model (e.g., Sissors and Bumba, 1996). According to this model, the effects of repetition will begin to have a diminishing return after a certain point of exposure and reach a maximum point, but the impact of repetition can be maintained if there is additional repetition. Thus, unlike the inverted-U model and S-shaped model, the concave model does not suggest a rapid decline in advertising effectiveness after the tedium point, given that there is additional repetition.

At this point, empirical evidence on the impact of repetition in web advertising is limited. Unlike other traditional media such as television and radio where message recipients have less freedom to choose information, the web provides users with unprecedented freedom to choose content, time, and even duration of information exposure at their own will. This is an important characteristic of the web that differentiates web 'users' from 'audiences' in traditional media. Researchers suggest that as the web gets older and more users become 'experienced' users, some users display a tendency to avoid banners on the web. For example, Benway and Lane (1998) investigated whether web users had a tendency to avoid banners in a task-oriented environment. Participants in their study were given the task of finding information in two ways: either by clicking on a small textual link or by looking at a large banner that displayed the task-relevant information. Surprisingly, 55 out of 72 participants found and clicked a small textual link but failed to see the information contained in the salient large banner. Specifically, the researchers found that the banners not only failed to grab users' attention, but also banners were frequently ignored. Thus, the researchers suggested that some web users have a tendency to avoid banners and concluded that the phenomenon is beyond advertising effects, suggesting that the impact of repetition on the web can be quite different from traditional media.

Pagendarm and Schaumburg (2001) examined behavioural wearout effects on the web. In their study, the click-through rate after the first exposure declined rapidly and reached less than $1 \%$ at the fourth exposure. They suggested that wearout effects on the web would differ from traditional media. Specifically, while the wearout in traditional media begins after a certain level of exposure, it would occur after the first exposure in the web environment.

One major issue in web advertising can be web users' inattention to web ads. Experienced web users, for example, tend to process the information components more rapidly and efficiently. Dreze and Zufryden (1999) suggested that experienced users automatically know where the banners and the information they want are located in a webpage. As a result, they may consciously or unconsciously avoid banner ads, leading to a kind of "banner blindness" (Benway and Lane, 1998). Empirical evidence, however, is still scarce as to how web users may respond to an increase in repetition.

\subsection{Effects of brand familiarity}

Brand familiarity has been generally known to have a positive impact on advertising effectiveness. In the advertising literature, overwhelming evidence suggests that familiar brands do have cognitive and attitudinal advantage over unfamiliar brands (see, for example, Miniard et al., 1990; Mitchell and Olson, 1981; Tellis, 1987). Further, the advantage for familiar brands goes far beyond memory. Consumers' familiarity with 
certain brands may have been established through product use, packaging, advertising and other forms of marketing communication over time. Accordingly, consumers may not only have memory for the brand name and the product attributes, but also certain attitudes toward the brand and the product.

Past research generally suggests that familiar brands result in differential information processing and brand evaluation. Hoch and Deighton (1989), for example, argue that for familiar brands, consumers tend to assimilate new information relevant to the familiar brands into preexisting knowledge structure more quickly. Accordingly, information on familiar brands tends to be processed more efficiently with less cognitive demands (Tellis, 1987). Perhaps this is because consumers' knowledge and attitudes about familiar brands are already established and relatively stable over time. On the other hand, consumers' prior knowledge and attitudes about unfamiliar brands may not be formed or are weak at best. Therefore, consumers' information processing and evaluations of ads would differ depending on the degree of brand familiarity. For example, it may require relatively fewer advertising exposures for familiar brands to deliver a new claim and generate attitude toward a new product while unfamiliar brands may need far more exposures in order to achieve the same impact.

Tellis (1997) argues that while response to familiar brand ads may take a convex curve as a function of repetition, responses to unfamiliar brand ads may yield an inverted convex curve. Specifically, Tellis $(1987 ; 1997)$ explains the advantages of familiar brands over unfamiliar brands in terms of the cognitive structure of consumers. First of all, consumers tend to interpret familiar brands in order to maintain cognitive consistency. Since people have a desire to maintain cognitive consistency, advertising relevant to consumers' existing opinion and attitudes would be processed more efficiently. Second, because consumers' attention, comprehension, and retention of ads are largely selective, familiar brands tend to receive greater attention than unfamiliar brands. In order words, people have limited attention capacity and familiar information may receive greater attention than unfamiliar information. Third, because consumers have more extensive prior experience with familiar brands, cognitive elaboration is more likely than with unfamiliar brands. In short, when consumers are faced with familiar brand ads, they utilise their prior experiences and preexisting knowledge in processing the new information. Thus, it seems clear that people could readily associate the new information in the familiar brand ads with the information they have already acquired.

Research showed that internet users tend to react more favourably to familiar brands when shopping online (Ward and Lee, 2000). Dahlen (2001) also found that familiar brand ads initially received more click-throughs than unfamiliar brand ads. However, there was no significant difference in terms of click-through rate between familiar and unfamiliar brands after the third exposure. Specifically, the banner click-through rate for familiar brands increased in the initial exposures but declined after the third exposure, whereas click-through rate for unfamiliar brands gradually increased. The results of this study are consistent with existing evidence that familiar brands tend to induce tedium faster than unfamiliar brands (Tellis, 1997; Mitchell and Olson, 1981).

In sum, it is expected that the impact of repetition in the web environment will manifest differently from what existing repetition models predict. While there could be other significant variables, brand familiarity in general has significant effects on advertising effectiveness and is expected to moderate the impact of repetition. 
For this study, existing research in new media does not provide clear evidence to formulate specific research hypotheses. Thus, the following two research questions are proposed to explore the impact of advertising repetition on the web:

\section{$R Q 1$ How does repetition interact with brand familiarity to affect advertising effectiveness on the web?}

$R Q 2$ How does repetition shape wearin and wearout effects on the web?

\section{Method}

\subsection{Product and brand selection}

First, two pretests were conducted to select the product category and the brand. The product selection was made on the premise that the product should be used by college students and have a moderate level of product involvement to avoid any product involvement bias. As a result for the first pretest $(N=35)$, the credit card met the guidelines and therefore was selected for the study. A second pretest $(N=20)$ tested brand familiarity among different credit cards and several mock brands. As a result, CapitalOne Visa card was selected as a familiar brand credit card and ValueSelect was selected as an unfamiliar brand.

\subsection{Design and study participants}

The study employed a 2 (brand familiarity: familiar or unfamiliar) $\times 6$ (repetition: $1,2,3$, 5,7 , and 9) factorial design. Although existing research in the traditional media generally suggests that tedium occurs around three exposures, repetition nine was selected as the maximum repetition in this study because tedium on the web may occur later due to the medium characteristics, e.g., interactivity.

For this study, participants were recruited from several classes in a large Mid-Eastern university in the US for extra credit. At the time of recruiting, participants were told that they would evaluate a beta website relevant to college students, which would be launched within several months. Participants were also informed that they would receive an e-mail within a couple of days and they should pay attention to the directions in the e-mail and the introductory webpage in order to complete the study and receive extra credit. After a couple of days, an e-mail was sent to the potential participants who had signed up in classes. As a result, two hundred and twenty two students participated in the study. Participants were largely in the age group of 18 to $23(97.5 \%)$, with $70 \%$ females.

\subsection{Stimulus websites/ads}

Twelve websites were created for this study. In order to create a more natural browsing environment, stimulus websites and banners were developed by a professional web designer. Each website consisted of a total of 11 webpages and contained short articles pertaining to college life (e.g., dorm life, handling homesickness, hanging out, being single, etc.). The contents of webpages were downloaded from several websites targeted toward college students and subsequently modified for length to fit the purpose of 
the study. Lastly, stimulus webpages were uploaded onto a website address, which was registered for this study. The contents of webpages kept constant across experimental conditions, and the only difference was the number (frequencies 1, 2, 3, 5, 7, and 9) and type of banner ads.

The standard $(728 \times 90$ pixels $)$ static banner format was adopted for the study (see Appendix). Stimulus banners (familiar or unfamiliar ad) were also designed by a professional, and the only difference between the two types of banners was the brand name, either familiar or unfamiliar.

\subsection{Experimental treatment conditions}

The stimulus banners were located at the top of webpages, and no banner was placed at the first and last pages to avoid any primacy and recency effects. In this study, however, no filler ads (i.e., non-target ads) were used because filler ads may confound repetition effects of the target ads. For example, participants in the repetition 1 condition saw 11 webpages, only 1 of which contained the stimulus banner with either a familiar or unfamiliar brand, while participants in the repetition 9 condition saw 11 webpages, 9 of which contained the same stimulus banner with either a familiar or unfamiliar brand.

\subsection{Procedure}

A forced exposure was adopted in the experiment so that the top portion of the webpage containing the ad was displayed 2 sec. earlier than the rest of the webpage. While this method may attract more attention from the participants than other types of exposures, it was considered ecologically valid because of the fact that this method is currently being used by many commercial websites in the real world and that when downloading speed is slow, banner ads are often displayed slightly earlier than the rest of the webpage.

An e-mail containing detailed instructions was sent to the potential participants who had signed up in class. The e-mail contained detailed instructions for the study. Upon receiving the e-mail, participants were led to the stimulus webpage by clicking the link in the e-mail. Participants were randomly assigned to one of 12 experimental conditions using JavaScript programming. After viewing stimulus webpages, participants were led to the questionnaire webpage displayed in a pop-up browser.

\subsection{Dependent measures}

Five dependent measures were used in this study. A free recall question was asked to measure participants' brand recall (i.e., Please the name of the brand in the ad you saw today). A brand name recognition question was also asked as a memory measure, (i.e., Which of the following was the brand name you saw in the ad?). Participants' Aad was measured by three seven-point semantic differential scale items anchored by "good/bad", "favorable/unfavorable", and "satisfactory/unsatisfactory" (Bruner and Hensel, 1992), $\alpha=.92$. Participants attitudes for the brand (Abrand) were measured by three seven-point semantic differential scale items anchored by "good/bad", "favorable/unfavorable", and "pleasant/unpleasant" (MacKenzie and Lutz, 1989), $\alpha=.91$. Finally, purchase intention was measured by seven-point semantic differential scales, "likely/unlikely", "probable/improbable", and "possible/impossible" (Lutz et al., 1983) $\alpha=.89$. 


\section{Results}

The data were first analysed with the two (brand familiarity) $\times$ six (repetition) factorial ANOVA to examine the main and interaction effects for brand familiarity and repetition (means and standard deviations are presented in Table 1). As can be seen in Table 2, brand familiarity had significant main effects on the two memory variables. However, no other significant main effects were observed for brand familiarity or repetition.

Table 1 Responses to repetition by experimental condition

\begin{tabular}{lcccccc}
\hline & \multirow{5}{*}{ Repetition } & \multicolumn{5}{c}{ Dependent means and standard deviations } \\
\cline { 2 - 6 } & & Recall & Recognition & Aad & Abrand & PI \\
\hline Familiar brand & 1 & $.20(.41)$ & $.60(.50)$ & $3.77(.82)$ & $3.75(.54)$ & $3.32(.92)$ \\
& 2 & $.13(.34)$ & $.75(.45)$ & $3.81(.53)$ & $4.10(.58)$ & $3.87(1.01)$ \\
& 3 & $.16(.37)$ & $.58(.51)$ & $3.93(.64)$ & $4.05(.51)$ & $3.95(1.04)$ \\
& 5 & $.21(.42)$ & $.58(.51)$ & $4.12(.69)$ & $4.02(.41)$ & $3.95(.66)$ \\
& 7 & $.26(.45)$ & $.63(.50)$ & $3.93(.78)$ & $3.95(.86)$ & $3.61(.74)$ \\
Unfamiliar & 9 & $.25(.44)$ & $.50(.51)$ & $3.68(.74)$ & $3.73(.76)$ & $3.60(.79)$ \\
brand & 1 & $.00(.00)$ & $.42(.51)$ & $4.18(.54)$ & $4.21(.69)$ & $3.65(.85)$ \\
& 2 & $.00(.00)$ & $.26(.45)$ & $3.88(.57)$ & $3.81(.75)$ & $3.67(.87)$ \\
& 3 & $.00(.00)$ & $.28(.46)$ & $3.80(.46)$ & $3.89(.40)$ & $3.52(.63)$ \\
& 5 & $.00(.00)$ & $.60(.50)$ & $3.62(.44)$ & $3.85(.57)$ & $3.37(.58)$ \\
& 7 & $.11(.32)$ & $.56(.51)$ & $3.72(.54)$ & $3.85(.55)$ & $3.46(.40)$ \\
& 9 & $.20(.41)$ & $.53(.52)$ & $3.84(.56)$ & $4.18(.45)$ & $3.90(.92)$ \\
\hline
\end{tabular}

Table 2 Univariate analysis results as a function of brand familiarity and repetition

\begin{tabular}{lccccc}
\hline & \multicolumn{5}{c}{ ANOVA (F-value) } \\
\cline { 2 - 6 } Source & $\begin{array}{c}\text { Brand } \\
\text { recall }\end{array}$ & $\begin{array}{c}\text { Brand } \\
\text { recognition }\end{array}$ & Aad & Abrand & $\begin{array}{c}\text { Purchase } \\
\text { intention }\end{array}$ \\
\hline Main effects & & & & & \\
Brand familiarity & $11.58^{* *}$ & $6.11^{*}$ & .18 & .14 & 1.30 \\
Repetition & 1.40 & .58 & .44 & .09 & .83 \\
Interaction effects & & & & & $2.73^{*}$ \\
$\quad$ Brand familiarity $\times$ repetition & .29 & .15 & $2.49^{*}$ & 2.04 \\
\hline
\end{tabular}

Notes: $\quad * p<.05$.

$* * p<.01$.

The interaction between brand familiarity and repetition was significant on Aad, $F(5,210)=2.49, p<.05$, partial $\eta^{2}=.06$, and Abr, $F(5,210)=2.73, p<.05$, partial $\eta^{2}=.06$, and marginally significant on purchase intention, $F(5,210)=2.04$, $p=.08$, partial $\eta^{2}=.05$. Figures 1,2 , and 3 illustrate these interactions. No significant interactions were found on the two memory variables. 
Figure 1 Interaction between brand familiarity and repetition on Aad (see online version for colours)

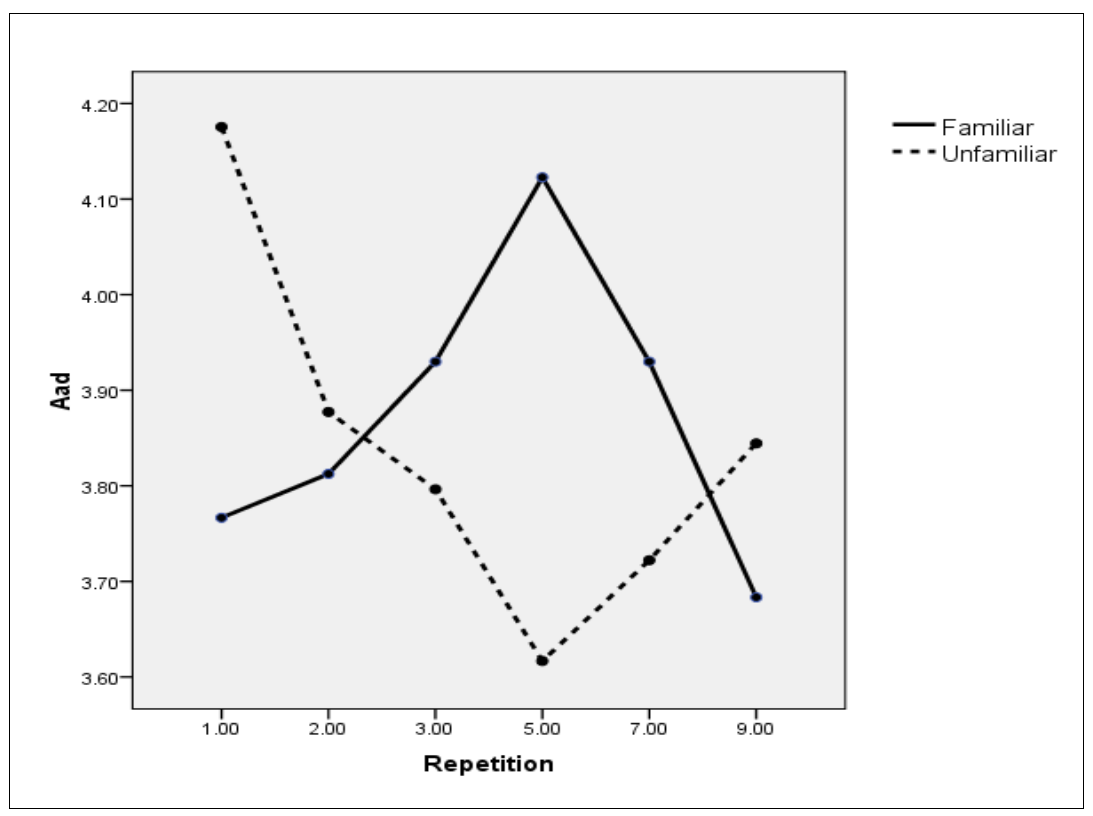

Figure 2 Interaction between brand familiarity and repetition on Abrand (see online version for colours)

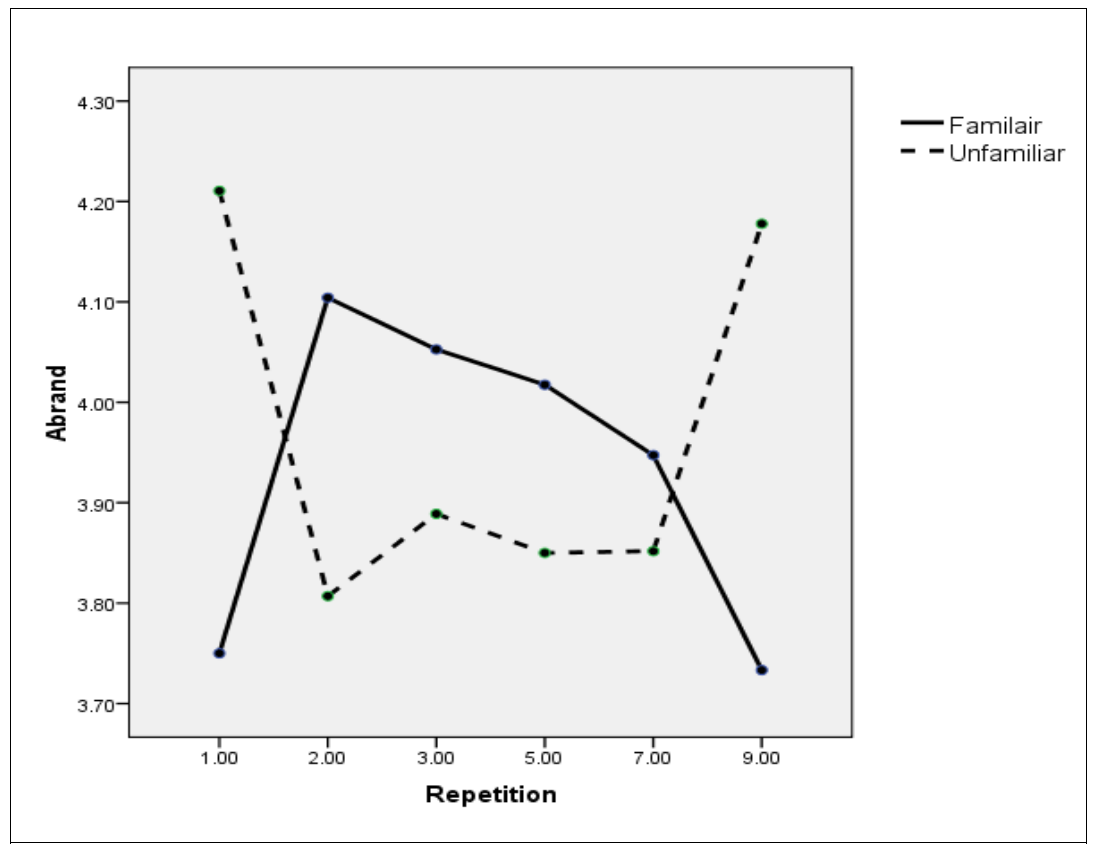


Figure 3 Interaction between brand familiarity and repetition on purchase intention (see online version for colours)

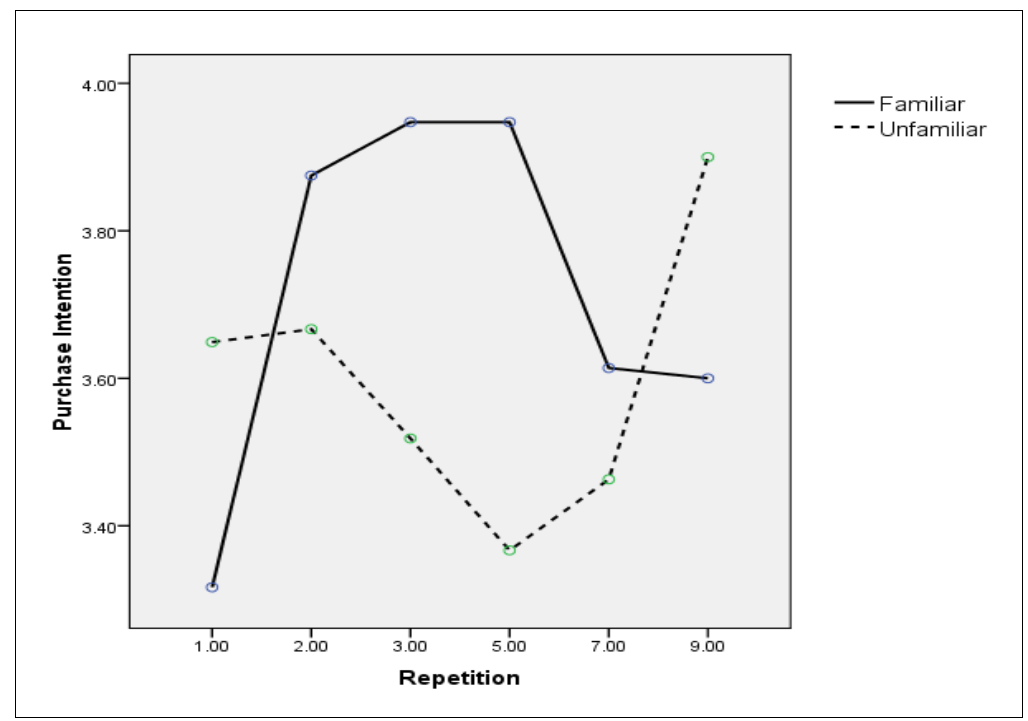

To examine the wearin and wearout patterns, a series of polynomial trend analyses were performed on the dependent variables for each of the two data subsets (familiar or unfamiliar brand). The regression model used in these analyses included first degree (i.e., linear), second degree (i.e., quadratic), and third degree (i.e., cubed) terms for repetition as an independent variable. Tables 3 and 4 report the trend analysis results.

Table 3 Polynomial trend analysis results of repetition for familiar brand

\begin{tabular}{lcccccc}
\hline Dependent variable & Model & R square & $d f 1$ & $d f 2$ & $F$ & Significance \\
\hline Brand recall & Linear & .00 & 1 & 110 & .47 & .49 \\
& Quadratic & .00 & 2 & 109 & .24 & .79 \\
\multirow{3}{*}{ Recognition } & Cubic & .01 & 3 & 108 & .39 & .76 \\
& Linear & .01 & 1 & 110 & 1.02 & .31 \\
& Quadratic & .01 & 2 & 109 & .62 & .54 \\
Aad & Cubic & .01 & 3 & 108 & .43 & .73 \\
& Linear & .00 & 1 & 111 & .03 & .86 \\
Abrand & Quadratic & .04 & 2 & 110 & 2.01 & .13 \\
& Cubic & .04 & 3 & 109 & 1.41 & .25 \\
\multirow{5}{*}{ Purchase intention } & Linear & .01 & 1 & 111 & .52 & .47 \\
& Quadratic & .04 & 2 & 110 & 2.20 & .12 \\
& Cubic & .04 & 3 & 109 & 1.67 & .18 \\
& Linear & .00 & 1 & 110 & .22 & .89 \\
\hline
\end{tabular}


Table 4 Polynomial trend analysis results of repetition for unfamiliar brand

\begin{tabular}{lllllll}
\hline Dependent variable & Model & $R$ square & $d f 1$ & $d f 2$ & $F$ & Significance \\
\hline Brand recall & Linear & .10 & 1 & 107 & 11.48 & .001 \\
& Quadratic & .12 & 2 & 106 & 7.26 & .001 \\
& Cubic & .12 & 3 & 105 & 4.80 & .004 \\
Recognition & Linear & .03 & 1 & 107 & 3.75 & .06 \\
& Quadratic & .04 & 2 & 106 & 1.92 & .15 \\
\multirow{4}{*}{ Aad } & Cubic & .06 & 3 & 105 & 2.06 & .11 \\
& Linear & .04 & 1 & 107 & 4.02 & .05 \\
Abrand & Quadratic & .11 & 2 & 106 & 6.21 & .03 \\
& Cubic & .11 & 3 & 105 & 4.27 & .07 \\
& Linear & .00 & 1 & 107 & .01 & .94 \\
Purchase intention & Quadratic & .06 & 2 & 106 & 3.11 & .05 \\
& Cubic & .06 & 3 & 105 & 2.12 & .10 \\
& Linear & .00 & 1 & 107 & .12 & .73 \\
& Quadratic & .04 & 2 & 106 & 2.45 & .09 \\
& Cubic & .05 & 3 & 105 & 1.88 & .14 \\
\hline
\end{tabular}

The trend analyses showed that the wearin and wearout patterns were not clearly evident for the familiar brand. Polynomial analyses resulted in no significant trends across the dependent variables (Table 2). For the unfamiliar brand ads, however, some significant relationships were observed. On recall, the first degree, $R^{2}=0.10, F(1,107)=11.48$, $p<0.001$, the second degree, $R^{2}=0.12, F(2,106)=7.26, p<0.001$, and the third degree, $R^{2}=0.12, F(3,105)=4.80, p<0.005$, terms were all significant. The significant effects on recall, however, were largely due to the lack of recall from repetition one through five (see Table 1 for means and standard deviations). On recognition, only the first degree term was marginally significant, $R^{2}=0.03, F(1,107)=3.75, p=0.06$. On Aad, the first degree, $R^{2}=0.04, F(1,107)=4.02, p<0.05$, and the second degree, $R^{2}=0.11, F(2,106)=6.21, p<0.05$, terms were significant, while the third degree term, $R^{2}=0.11, F(3,105)=4.27, p=0.07$, was marginally significant. On Abrand, only the second degree term, $R^{2}=0.06, F(2,106)=3.11, p<0.05$, was significant. On purchase intention only the send degree term, $R^{2}=0.04, F(2,106)=2.45, p=0.09$, was marginally significant.

In sum, the results showed relatively weak main effects for the two independent variables across the dependent measures. For the familiar brand ads, no significant interactions or trends were found, whereas some significant interactions and trends were found for the unfamiliar brand ads.

\section{Discussion}

The purpose of the study was to examine the repetition effects under differing brand familiarity conditions as well as to explore the wearin and wearout patterns in the web advertising context. The results generally showed that while advertising repetition 
had weak main effects across the dependent variables, brand familiarity had significant main effects on the memory variables but not on the attitudinal variables or purchase intention. The lack of main effects for these two independent variables is not surprising. Compared to audiences in traditional media, web users' level of attention to ads is very low, as banner blindness (Benway and Lane, 1998) and banner burnout (Pagendarm and Schaumburg, 2001) suggests. Thus, while a familiar brand may have a mnemonic advantage and possibly have more possibility to be noticed by web users, an unfamiliar brand may not be noticed until the ad is repeated multiple times.

Repetition and brand familiarity, however, interacted on Aad and Abrand and showed a marginally significant interaction effect on purchase intention. The two significant interaction effects (i.e., Aad and Abrand) were somewhat similar in their patterns: Familiar brand ads showed an inverted-U curve response pattern while unfamiliar brand ads showed a $U$ curve response pattern.

In examining the wearin and wearout effects, the polynomial trend analyses showed no significant patterns for the familiar brand ads across the dependent variables. Thus, this research was not able to identify any consistent patterns of wearin or wearout for familiar brand ads within the current research framework. This does not mean, however, that there is no wearin or wearout on the web. This research employed only one through nine repetitions and it is possible that more repetition may be necessary to observe significant wearin and wearout patterns for familiar brand ads on the web.

For the unfamiliar brand ads, data analyses revealed some significant trends, which suggest potential wearin and wearout patterns as a function of repetition. On recall of the unfamiliar brand, trend analyses showed significant linear, quadratic, and cubic changes. These significant results are, however, largely due to the lack of recall from one through five repetitions. There were virtually no recall scores reported from one through five repetitions. Only the participants in seven and nine repetition conditions reported recall of the brand in the ad. Thus, based on the data analyses, recall of an unfamiliar brand may start to wearin after five repetitions. Accordingly, within the framework of the current research, it is not clear at which point of repetition wearout may occur. On recognition of the unfamiliar brand, only a marginally significant linear change was observed.

On Aad, both linear and quadratic terms were significant for the unfamiliar brand ads. Data analyses clearly showed a pattern affected by repetition of ads. Specifically, while there was a significant overall decrease from one repetition, Aad began to wearin after five repetitions, displaying a U-type response. On Abrand, only the quadratic term was significant. This pattern was somewhat similar to Aad: Abrand wore off slightly from one to two repetitions, but not enough to be a significant linear change, and then levelled off until seven repetitions. Abrand, however, began to wearin from seven to nine repetitions, showing a U-type response. Thus, interestingly, both Aad and Abrand scores were highest at one repetition and showed a rather stiff decrease. Aad and Abrand scores then began to wearin again as the repetition continued. On purchase intention, although the trend analyses showed only the marginally significant quadratic trend, the pattern of the repetition effects was somewhat similar to Aad and Abrand.

The current research indicated that advertising wearin and wearout patterns on the web can be very different from traditional media, and suggests that web advertising may need different theoretical considerations. The significant patterns observed for the unfamiliar brand ads on Aad, Abrand and purchase intention were counterintuitive to existing repetition theories such as Three-Hit theory or Two-Factor theory. While 
advertising response in traditional media involves an increasing or wearin phase in the initial exposure stage, the current study showed that advertising response on the web can take a different response, at least for unfamiliar brand ads. The results showed that, for the unfamiliar brand ads, the impact of the first exposure is greater than the second or third exposure, whereas in traditional media, the impact of first exposure tends to be much weaker than the second or the third exposure. The response patterns of the familiar brand ads on Aad, Abrand and purchase intention, however, took an inverted-U response, although the trends were not significant.

There are several limitations in this study. First, college student participants, for example, may limit the generalisability of the findings, given that college students are considered expert web users. Secondly, in the real world, ads are often placed in a competitive and cluttered environment. As Schumann and Clemons (1989) argued, the perception of repetition is also dependent on the number of competing ads on a given stimulus. Third, using a specific size and type of banner also limits the generalisability of the study. Specifically, the study employed a static banner $(720 \times 90$ pixels $)$, but banner ads in the real world vary in terms of sizes, shapes, location and modality. Therefore, caution should be exercised in generalising the results of this study to other forms of online ads. Finally, one potentially confounding factor pertaining to the overall findings in this study should be mentioned. Given that most web users have some type of task in mind when they access to the web, this study used the articles relevant to the sample, i.e., articles about college life. Although using media content relevant to the sample would be more ecologically valid, it appears that participants' involvement with the content might have been too high, possibly resulting in less attention to the banner ads. For example, participants' involvement with the content tends to be relatively high, measured by Zaichkowsky (1994) personal involvement inventory, $M=4.7, \mathrm{SD}=1.2$. Past research in traditional media has suggested that high content involvement tends to decrease advertising effectiveness because audiences are more engaged in the media content.

Future studies can benefit by employing other variables that may moderate the impact of repetition. In order to understand the role of repetition and wearin and wearout patterns, it is critical to understand how repetition interacts with other potentially important variables such as product involvement, or advertising appeals. The results reported here may be different if other variables come into play.

Future research can also benefit by employing different levels of repetition. As stated earlier, the wearin and wearout points may lie beyond the repetition employed in this study. Research has indicated that web users spend only a short span of time on banner ads when they browse the web (Lewenstein et al., 2000), which provides an important implication in terms of depth of information processing. From an information processing perspective, a certain amount of time is needed to effectively process the information on a stimulus. When information is processed during a short span of time, it is likely that encoding of information can be 'shallow' rather than 'deep'. Accordingly, the impact of repetition can be weaker than in traditional media, which will lead to different wearin and wearout patterns. 


\section{References}

Benway, J.P. and Lane, D.M. (1998) 'Banner blindness: the irony of attention grabbing on the world wide web', Proceedings of the Human Factors and Ergonomics Society 42nd Annual Meeting, Vol. 1, pp.463-467.

Berlyne, D. (1970) 'Novelty, complexity, and hedonic value', Perception and Psychophysics, Vol. 8, pp.279-286.

Bruner, G. and Hensel, P. (1992) Marketing Scales Handbook: A Compilation of Multi-Item Measures, Chicago, IL: American Marketing Association.

Burnkrant, R. and Unnava, H. (1987) 'Effects of variation in message execution on the learning of repeated brand information', Advances in Consumer Research, Vol. 16, pp.173-176.

Cacioppo, J. and Petty, R. (1979) 'Effects of message repetition and position on cognitive response, recall, and persuasion', Journal of Personality and Social Psychology, Vol. 37, pp.97-109.

Dahlen, M. (2001) 'Banner advertisements through a new lens', Journal of Advertising Research, Vol. 41, No. 4, pp.23-30.

Dreze, X. and Zufryden, F. (1999) 'Internet advertising: is anybody watching?', Journal of Advertising Research, Vol. 57, pp.60-79.

Hoch, S. and Deighton, J. (1989) 'Managing what consumers learn from experience', Journal of Marketing, Vol. 53, pp.1-20.

Krugman, H.E. (1972) 'Why three exposures may be enough', Journal of Advertising Research, Vol. 12, No. 6, pp.11-14.

Lewenstein, M., Edwards, G., Tatar, D. and DeVigal, A. (2000) Stanford-Poynter Project, http://www.poynter.org/eyetrack2000/.

Lutz, R., MacKenzie, S. and Belch, G. (1983) 'Attitude toward the ad as a mediator of advertising effectiveness: determinants and consequences', in R. Bagozzi and A. Tybout (Eds.) Advances in Consumer Research, Ann Arbor, Michigan, Vol. 10, pp.532-539.

MacKenzie, S.B. and Lutz, R.J. (1989) 'An empirical examination of the structural antecedents of attitude toward the ad in the advertising pretesting context', Journal of Marketing, Vol. 53, pp.48-65.

Miniard, P., Bhatla, S. and Rose, R. (1990) 'On the formation and relationship of ad and brand attitudes: an experimental and causal analysis', Journal of Marketing Research, Vol. 27, pp.290-303.

Mitchell, A. and Olson, J. (1981) 'Are product attribute beliefs the only mediator of advertising effects on brand attitude?', Journal of Marketing Research, Vol. 18, pp.318-332.

Pagendarm, M. and Schaumburg, H. (2001) 'Why are users banner-blind? The impact of navigation style on the perception of web banners', Journal of Digital Information, Vol. 2, No. 1, http://jodi.ecs.soton.ac.uk/Articles/v02/i01/Pagendarm/.

Pechmann, C. and Stewart, D. (1988) 'Advertising repetition: a critical review of wearin and wearout', Current Issues and Research in Advertising, Vol. 11, pp.285-329.

Schumann, D. and Clemons, D. (1989) 'The repetition/variation hypotheses: conceptual and methodological issues', Advances in Consumer Research, Vol. 16, pp.529-534.

Schumann, D., Petty, R. and Clemons, D. (1990) 'Predicting the effectiveness of different strategies of advertising variation: a test of the repetition-variation hypotheses', Journal of Consumer Research, Vol. 17, pp.192-201.

Sissors, J. and Bumba, L. (1996) Advertising Media Planning, Lincoln, IL: NTC Business Books.

Tellis, G. (1987) 'Advertising exposure, loyalty, and brand purchase: a two stage model of choice', Journal of Marketing Research, Vol. 15, pp.134-144.

Tellis, G. (1997) 'Effective repetition: one exposure or three factors?', Journal of Advertising Research, Vol. 37, No. 4, pp.75-80.

Ward, M. and Lee, M. (2000) 'Internet shopping, consumer search and product branding', Journal of Product and Brand Management, Vol. 9, pp.6-18.

Zaichkowsky, J. (1994) 'The personal involvement inventory: reduction, revision, and application to advertising', Journal of Advertising, Vol. 23, No. 4, pp.59-70. 


\section{Appendix}

Sample target banners

Familiar brand (see online version for colours)

\begin{tabular}{|c|c|c|}
\hline $\begin{array}{c}\text { CapitalOne } \\
\text { VIsA }\end{array}$ & $\begin{array}{l}\text { Need a credit card? } \\
: 5.99 \% \text { Fixed APR for } 6 \text { months! } \\
: \text { Credit limit tupto } \$ 20,000 \\
\text { Flexible Student Payment Plan® }\end{array}$ & Apply Now! \\
\hline
\end{tabular}

Unfamiliar brand (see online version for colours)

\begin{tabular}{|cll|}
\hline Value Select & Need a credit card? & \\
VIsA & $: 5.99 \%$ Fixed APR for 6 months! & Apply Now! \\
\hline
\end{tabular}

